\title{
A INFLUÊNCIA DA COOPERATIVA UNITÁ NA MOBILIDADE DA POPULAÇÃO PARA O MUNICÍPIO DE UBIRATÃ-PARANÁ
}

\author{
Débora Vanessa Felipe da Silva ${ }^{1}$, Fábio Rodrigues da Costa $^{2}$, Cláudia Chies ${ }^{3}$
}

\begin{abstract}
${ }^{1}$ Licenciada em Geografia, Pós-graduação em Geografia pela UNESPAR - campus de Campo Mourão. Professora em Ubiratã. E-mail: debora_vanessa10@hotmail.com. ORCID: http://orcid.org/0000-0002-3349-7768

${ }^{2}$ Licenciado em Geografia, Mestre e Doutor em Geografia pela UEM, professor do Colegiado de Geografia e do Mestrado Interdisciplinar PPGSeD na UNESPAR - campus de Campo Mourão. E-mail: frcosta79@gmail.com, fabio.costa@ies.unespar.edu.br. ORCID: http://orcid.org/0000-0002-4708-1480

${ }^{3}$ Licenciada em Geografia, Mestre e Doutora em Geografia pela UEM, professora do Colegiado de Geografia da UNESPAR - campus de Campo Mourão. E-mail: claudia.chies@ies.unespar.edu.br. ORCID: http://orcid.org/0000-00016054-6679
\end{abstract}

Artigo recebido em 28/10/2019 e aceito em 27/02/2021

\section{RESUMO}

A presente pesquisa objetivou analisar a mobilidade física e centrada no trabalho da população para o município de Ubiratã-PR, em virtude da instalação da Cooperativa Unitá no ano de 2013. A Cooperativa Unitá nasceu da parceria entre a Cooperativa Copacol, a Cooperativa Coagru e a Cooperflora. Desde a instalação da Cooperativa, o abatedouro é responsável pela geração de quase três mil empregos diretos e indiretos, fato que ocasionou novo dinamismo demográfico no município, atraindo pessoas de várias partes do Brasil e até de outro país. Para a realização da pesquisa adotou-se a metodologia quali-quantitativa, que envolveu levantamentos bibliográficos e análise de dados. Dessa forma, a pesquisa avaliou o impacto da avicultura nos processos migratórios de 2013 até 2018 no município de Ubiratã.

Palavras-chave: Mobilidade da população; Cooperativa; Avicultura.

\section{UNITÁ COOPERATIVE INFLUENCES ON THE POPULATION'S MOBILITY TO THE MUNICIPALITY OF UBIRATÃ-PR}

\begin{abstract}
This research aimed to analyze the population mobility to the municipality of Ubiratã due to the installation of Unitá Cooperative in 2013. Unitá Cooperative was created from the partnership among Copacol Cooperative, Cooperative Coagru and Cooperflora Cooperative. Since the establishment of the Cooperative, the slaughterhouse has been responsible for the generation of almost three thousand direct and indirect employments, a fact that has caused a new demographic dynamism in the municipality, attracting people from various parts of Brazil and even from other countries. To conduct the research, the qualitative and quantitative methodology was adopted, which involved bibliographic surveys and data analysis. Thus, the research evaluated the impact of poultry farming on migratory processes from 2013 to 2018 in the municipality of Ubiratã.
\end{abstract}

Keywords: Population Mobility; Cooperative; Poultry farming. 


\title{
LA INFLUENCIA DE LA COOPERATIVA UNITÁ EN LA MOVILIDAD DE LA POBLACIÓN PARA EL MUNICIPIO DE UBIRATÃ-PR
}

\begin{abstract}
RESUMEN
Esta investigación tiene como objetivo analizar la movilidad física y centrada en el trabajo para el municipio de Ubiratã, debido a la instalación de Cooperativa Unitá en 2013. Cooperativa Unitá nació de la alianza entre Cooperativa Copacol, Cooperativa Coagru y Cooperflora. Desde la instalación de la Cooperativa, el matadero ha sido responsable de la generación de casi tres mil empleos directos e indirectos, hecho que ha provocado un nuevo dinamismo demográfico en el municipio, atrayendo a personas de diversas partes de Brasil e incluso de otro país. Para la realización de la investigación se adoptó la metodología cualitativa y cuantitativa, que involucró levantamientos bibliográficos y análisis de datos. Así, la investigación evaluó el impacto de la avicultura en los procesos migratorios de 2013 a 2018 en el municipio de Ubiratã.
\end{abstract}

Palabras clave: Movilidad poblacional; Cooperativa; Avicultura.

\section{INTRODUÇÃO}

A geração de empregos é uma das maiores dificuldades enfrentadas por municípios de pequeno porte demográfico situados no interior do estado do Paraná. Nesses municípios o desemprego e a baixa remuneração são fatores que estimulam a migração da população, especialmente de jovens, em direção aos centros urbanos de maior dinamismo. Tal fato tem ocasionado no transcorrer das últimas três décadas, a redução da população total em um número significativo de municípios paranaenses.

Encontrar alternativas para reverter o quadro instalado é um dos desafios para os gestores públicos, bem como para a sociedade em geral. Nesse sentido, alguns munícipios tem procurado estabelecer iniciativas direcionadas para a geração de empregos, entre elas está a instalação de cooperativas que atuam na área da avicultura.

Com base no exposto, a presente pesquisa objetivou analisar a mobilidade física e centrada no trabalho da população para o município de Ubiratã, em virtude da instalação da Cooperativa Unitá. Presumiu-se que os empregos gerados pela cooperativa estão alterando a dinâmica populacional do referido município. Para verificar o fato exposto, foi estabelecido um recorte temporal de 2013 a 2018 , visto que a Cooperativa Unitá foi formada em 2013, em parceria com outras três cooperativas: Cooperflora; Coagru e Copacol.

O objetivo geral do estudo foi avaliar se a instalação da cooperativa e a atividade de avicultura têm gerado os empregos capazes de reduzir o processo de esvaziamento populacional, bem como de atrair população de outras localidades para o município de Ubiratã. A pesquisa justifica-se pela necessidade de entender a dinâmica desse processo migratório, destacando suas implicações para o 
município. Partindo dessa perspectiva, apresenta-se como hipótese um possível aumento da população total em Ubiratã.

O problema que norteou o desenvolvimento da pesquisa diz respeito à procura de respostas para o seguinte questionamento: os empregos gerados pela Cooperativa Unitá estariam contribuindo para a mobilidade física e centrada no trabalho de população com destino a Ubiratã, assim como para a redução da evasão de população observada nas últimas décadas?

Os procedimentos metodológicos utilizados foram: a pesquisa bibliográfica e a análise qualiquantitativa. A construção científica está estruturada da seguinte forma: discussão teórica do conceito de mobilidade humana; contextualização histórica e geográfica do município de Ubiratã (sua localização e indicadores da economia); e análise da dinâmica da população entre 1970 e 2010. Também levou-se em consideração a modernização da agricultura e a sua influência na redução da população, principalmente a partir da década de 1970. Outros temas analisados foram a formação dos complexos agroindustriais, a implantação da Cooperativa Unitá em Ubiratã e a mobilidade física e centrada no trabalho da população, foco da pesquisa.

Para a realização do estudo foram feitas, em um primeiro momento, pesquisas bibliográficas com base em artigos de periódicos; dissertações; teses; livros; capítulos de livro; entre outros. Em um segundo momento foi realizada análise dos dados em relação aos funcionários que trabalham na Unitá e vieram de outras cidades do país. Com base nos resultados foram elaboradas as tabelas, os gráficos e o mapa retratando o fluxo de mobilidade espacial, ou seja, representando de quais lugares os trabalhadores vieram.

\section{A MOBILIDADE DA POPULAÇÃo}

O deslocamento de pessoas entre países, regiões, estados e municípios é um fenômeno antigo, amplo e muito complexo, pois envolve inúmeras questões. Os motivos que levam a mobilidade da população são diversos e apresentam consequências positivas e negativas, dependendo das condições e dos diferentes contextos socioeconômicos, culturais e ambientais em que ocorrem.

Os estudos atuais a respeito da mobilidade da população envolvem múltiplas dimensões, tais como: mudanças sociais; crises econômicas; problemas ambientais; disputas políticas e geopolíticas; fatores pessoais; ciclos de desenvolvimento; entre outros. Tais dimensões podem ser analisadas em conjunto ou separadamente. Quando estudadas separadamente é importante não perder de vista que estão inseridas em processos mais amplos, como é o caso da globalização. 
Guerras internacionais e civis, desastres ambientais, rupturas de territórios ocasionados por interesses políticos, o dinamismo econômico alcançado por alguns países (como os Estados Unidos, o Japão e a Austrália) e a pobreza em outros, são algumas das questões que norteiam a mobilidade da população no mundo, bem como no interior das regiões em busca de um recomeço e/ou oportunidade profissional. Cunha (2011) relatou a necessidade de analisarmos os novos pressupostos e conceitos em torno da mobilidade espacial da população:

[...] pensar de maneira mais geral na mobilidade espacial da população talvez fosse o mais adequado para nos desprendermos tanto de certos pressupostos e visões ultrapassadas que nos acompanharam até pouco tempo, quanto para vislumbrar novos conceitos, novas relações entre estes movimentos populacionais e, mais que isso, novas formas de compreender a dinâmica demográfica de nosso país e mais especificamente de nossas cidades e aglomerações urbanas (CUNHA, 2011. p. 12).

Atualmente os estudos de mobilidade da população no Brasil acompanham a tendência mundial de analisar o fenômeno para além da mobilidade rural-urbano de décadas anteriores. A mobilidade também está pautada em problemas ambientais (como a ruptura da barragem de rejeitos em Brumadinho no estado de Minas Gerais), conflitos agrários no norte do país entre grileiros, posseiros e população indígena (comuns no estado do Pará), a atração para os centros dinâmicos (como os situados na região Centro-Sul) e até mesmo a oferta crescente de empregos na indústria de aves (caso de alguns municípios localizados no interior do estado do Paraná). Os casos sinalizados são exemplos de como a dinâmica da população está em constante transformação, como bem explicou Damiani (2004).

Dentro do contexto apresentado evidencia-se que os estudos de mobilidade da população, em um espaço geográfico cada vez mais urbanizado e globalizado adquiriram novos contornos a partir de um olhar para as questões geopolíticas, ambientais, sociais, interpessoais, entre outras. No entanto, não se pode perder de vista que a mobilidade de população em busca de trabalho continua sendo intensa. Nesse quesito, a pesquisa elaborada por Gaudemar (1977) é esclarecedora.

O referido autor analisou a relação entre produção e força de trabalho, compreendendo a força de trabalho como uma mercadoria capaz de transformar o dinheiro em capital (GAUDEMAR, 1977). Diferente do que ocorreu nos modos de produção anteriores, no capitalismo a força de trabalho é livre, porém apenas para ser negociada em um mercado de trabalho.

[...] vê-se desenharem-se como formas contingentes desta "liberdade" de compravenda de força de trabalho as formas de uma mobilidade capitalista do trabalho. A mobilidade da força de trabalho é assim introduzida, em primeiro lugar, como 
condição de exercício da sua "liberdade" de se deixar sujeitar ao capital, de se tornar a mercadoria cujo consumo criará o valor e assim produzirá o capital (GAUDEMAR, 1977, p. 190).

Nesse contexto, a força de trabalho precisa ser móvel com a finalidade de atender a demanda das localidades nas quais os investimentos do capital são realizados, e esse movimento é denominado por Gaudemar (1977), de mobilidade física ou geográfica. Isso significa que a necessidade de emigração e de reabsorver parte do exército industrial de reserva em outro lugar, é fundamental para a reprodução do capital em nível global. Nesse sentido, os capitalistas procuram eliminar todos os obstáculos que inibem a extração de lucro, submetendo o trabalhador às exigências do capital. O que de fato observamos é: “[...] uma submissão cada vez maior do trabalho ao capital” (GAUDEMAR, 1977, p. 401).

No caso do Brasil, em virtude do acelerado processo de urbanização, a mobilidade da população adquiriu maior dinamismo e complexidade nas últimas décadas, pois ao mesmo tempo em que o país foi ficando cada vez mais integrado em redes de trocas comerciais de alcance regional e internacional, contraditoriamente, as desigualdades socioeconômicas continuaram intensas. A mobilidade do trabalho no interior do país continua atendendo prioritariamente aos interesses dos capitalistas, em detrimento das reais necessidades dos trabalhadores.

A partir da década de sessenta a população urbana supera a rural. As maciças migrações internas transitam pelo mercado de trabalho nacionalmente integrado acelerando, ao mesmo tempo, o processo de urbanização e metropolização. Esse novo perfil da sociedade brasileira, urbana, metropolitana e industrial, tem a marca estrutural das migrações internas que, simultaneamente, colaboraram para a constituição de uma sociedade nacionalmente integrada, mas com fortes desequilíbrios regionais e sociais (BRITO; RIGOTTI; CAMPOS, 2012, p. 7).

Para avançarmos na discussão exposta, apresentamos na sequência da pesquisa a noção geográfica de mobilidade humana e seus desdobramentos em mobilidade física, mobilidade centrada no trabalho e mobilidade social.

\section{A NOÇÃO DE MOBILIDADE HUMANA: física, centrada no trabalho e social}

A noção de mobilidade humana, elaborada por Rocha (1998), tem oferecido contribuição científica relevante para o entendimento dos caminhos percorridos por um grupo populacional no espaço geográfico. Nesse sentido: 
A mobilidade enquanto categoria científica é utilizada constantemente para explicar os movimentos dos homens em suas diversas instâncias. Os estudos populacionais, as migrações e mobilidade são noções que tratam de investigar a dinâmica de desenvolvimento das sociedades. No que concerne à geografia, busca-se o nexo territorial deste fenômeno tão amplo e complexo (ROCHA, 1998, p.17).

A mobilidade humana se subdivide em: mobilidade física; mobilidade centrada no trabalho e mobilidade social. A mobilidade física está relacionada aos movimentos horizontais e se subdivide em: macromobilidade física e micromobilidade física. A macromobilidade física diz respeito aos movimentos em escala internacional, nacional, estadual e municipal. A micromobilidade física referese aos deslocamentos cotidianos, como ir ao trabalho ou às compras (ROCHA, 1998).

Para Villaça (2001), as micromobilidades humanas também são responsáveis pela (re)estruturação do espaço urbano. Esse fato pode ser observado principalmente nas grandes metrópoles, como é o caso de São Paulo, porém também se faz presente nas demais cidades, visto que a micromobilidade faz parte das relações humanas cotidianas realizadas no território.

A mobilidade centrada no trabalho ocorre em função da dinâmica do mercado de trabalho e pode ser considerada como de caráter forçado, visto que o trabalhador é colocado em movimento em virtude das necessidades dos empregadores. O trabalhador precisa obter dinheiro para sobreviver, assim depende da lógica imposta pelos empregadores para conseguir trabalhar. Em relação às características desse tipo de mobilidade:

Esta ordem de mobilidade é uma mobilidade horizontal, ou seja, o deslocamento se dá no âmbito da qualificação dos indivíduos, de seu status profissional, da produtividade do trabalho, de sua condição funcional e de sua submissão à lógica capitalista de acumulação. [...] Esta força de trabalho é entendida como uma mercadoria especial que se desloca em função da dinâmica do mercado (ROCHA, 1998, p. 140).

Considerando que a grande maioria da população depende de um emprego para sobreviver, a necessidade de obter uma fonte de renda torna-se um fator que influencia diretamente na mobilidade de um elevado número de trabalhadores entre as empresas, entre as diferentes funções e setores, e até mesmo exige a migração para regiões mais prósperas e dinâmicas (áreas de atração de capitais e trabalhadores). Por sua vez, nas áreas que desempenham funções predominantemente periféricas o que se observa é o esvaziamento populacional com sérias implicações sociais (COSTA, 2016). 
Assim, para os trabalhadores, a mobilidade pode sim estar vinculada às demandas do mercado de trabalho, mas também é preciso considerar questões como segurança, qualidade de vida e a identificação/pertencimento ao lugar.

A mobilidade social, segundo Rocha (1998, p. 15) é um movimento vertical, visto que: “[...] trata de interpretar a mudança de status social dos indivíduos, sua posição e estruturas de classes e o movimento de polarização das classes sociais". A mobilidade social está diretamente relacionada com as possibilidades de mudança na posição social, por isso é um movimento vertical.

Dessa forma, essa pesquisa está pautada no estudo da mobilidade humana, com ênfase na análise da mobilidade física e da mobilidade centrada no trabalho para o município de Ubiratã. Tratase de uma mobilidade, na maioria das vezes forçada, e com o intuito de atender às demandas do capital por mão de obra. Nesse percurso, os trabalhadores estão submetidos aos interesses dos capitalistas.

\section{PROCEDIMENTOS METODOLÓGICOS}

Uma pesquisa é feita por meio de procedimentos e técnicas que permitem abstrair a realidade e transformá-la em conhecimento, a partir de certos critérios previamente adotados. Com isso, é possível chegar a um resultado confiável. Os procedimentos metodológicos utilizados para a elaboração da presente pesquisa foram: levantamento teórico/bibliográfico e a análise qualiquantitativa.

A pesquisa bibliográfica consiste no levantamento de obras relacionadas ao tema, bem como na sistematização das informações para posterior análise e interpretação. Severino (2007) explicou o conceito de pesquisa bibliográfica:

[...] registro disponível, decorrente de pesquisas anteriores, em documentos impressos, como livros, artigos, teses etc. Utilizam-se dados de categorias teóricas já trabalhadas por outros pesquisadores e devidamente registrados. Os textos tornamse fontes dos temas a serem pesquisados. O pesquisador trabalha a partir de contribuições dos autores dos estudos analíticos constantes dos textos (SEVERINO, 2007, p. 122).

Realizar uma pesquisa bibliográfica vai muito além da leitura dos trabalhos já realizados, deve ser uma forma de descobrimento e exploração do tema proposto, uma forma de reflexão e análise 
acerca do objeto de estudo, pois é desses momentos de reflexão que irão nascer outras ideias que agregarão maior valor ao trabalho (SEVERINO, 2007).

Quanto ao levantamento de dados a campo, elaborou-se um roteiro para realização de visitas à Cooperativa Unitá, para obtenção de informações junto aos gestores, referentes à produção, exportação, crescimento no número de trabalhadores na empresa e o local de origem dos trabalhadores que migraram para Ubiratã.

Para análise das informações das pessoas que se mudaram para a cidade de Ubiratã, em virtude da obtenção do emprego na Cooperativa Unitá, foi estabelecido um recorte temporal correlacionando a data em que o trabalhador começou a atuar na Cooperativa e a data em que chegou a Ubiratã. $\mathrm{O}$ recorte foi de seis meses da chegada a Ubiratã até começar a trabalhar na Cooperativa. Tal fato aproxima a correlação entre a migração e a obtenção do emprego.

Assim, foram investigadas as seguintes questões: 1) o número de empregos gerados pela Cooperativa; 2) os processos migratórios vinculados à oferta de empregos e; 3) a influência da Cooperativa na dinâmica da população.

Também foram coletados dados no site da Cooperativa Unitá, nas publicações da revista elaborada pela própria Cooperativa, no site de Instituto Brasileiro de Geografia e Estatística (IBGE), do Instituto Paranaense de Desenvolvimento Econômico e Social (IPARDES) e na prefeitura do município de Ubiratã. Após os referidos levantamentos, organizou-se tabelas, gráficos, quadros, entre outras ilustrações, e analisou-se os dados correlacionando-os com o debate teórico.

\section{BREVE CONTEXTUALIZAÇÃO SOBRE O MUNICÍPIO DE UBIRATÃ}

O município de Ubiratã apresenta área territorial total de $652,58 \mathrm{~km}^{2}$, localiza-se na região Sul do Brasil, no estado do Paraná, especificamente na Mesorregião Centro Ocidental Paranaense, conforme (figura 01). A sede municipal encontra-se a uma altitude de 508 metros acima do nível do mar. De acordo com o IBGE (2018), faz limite com os municípios de Nova Aurora, Corbélia, Quarto Centenário, Rancho Alegre d'Oeste, Juranda, Campina da Lagoa, Braganey, Iguatu e Anahy. 
FIGURA 1 - LOCALIZAÇÃO DA ÁREA DE ESTUDO

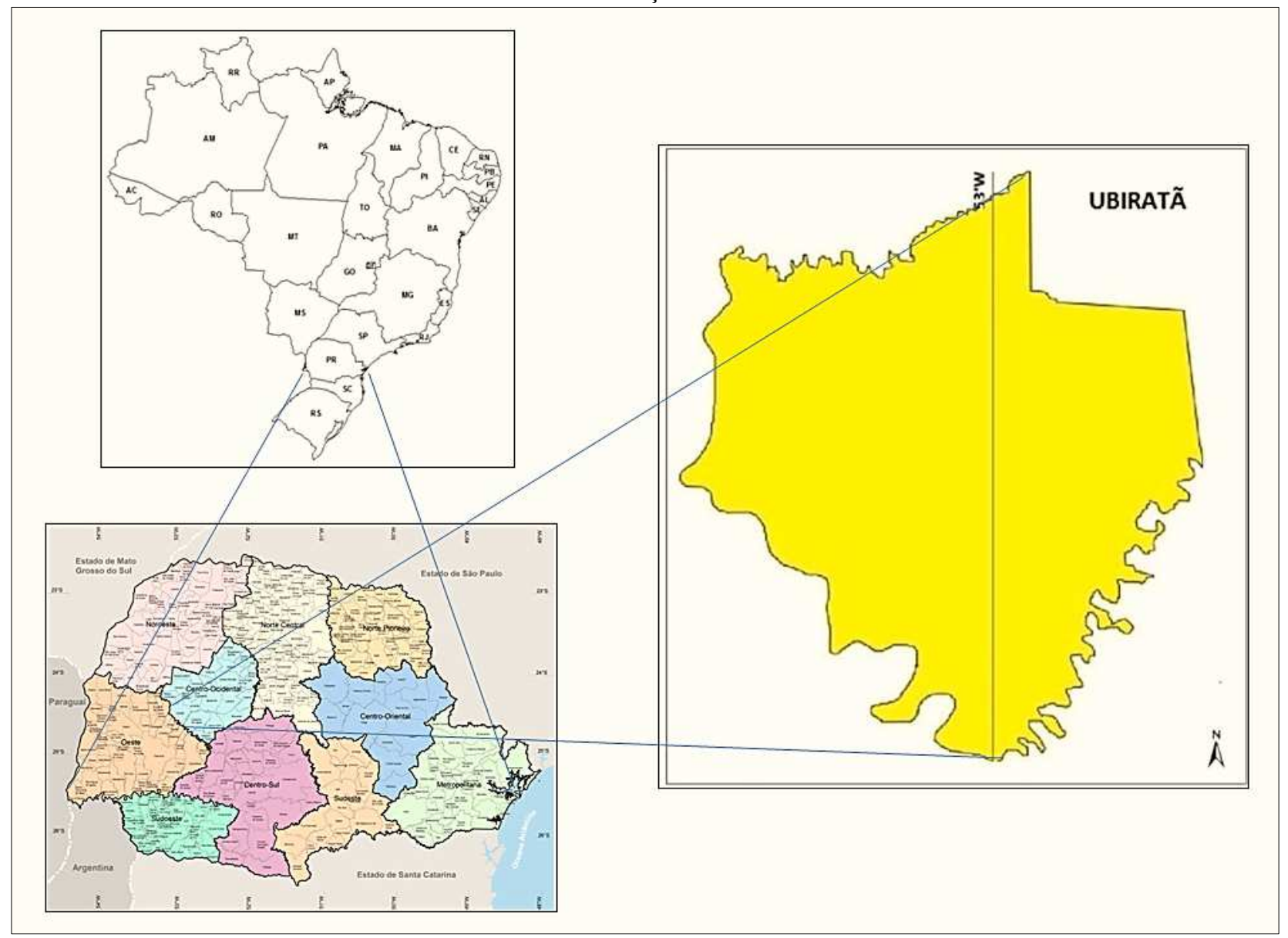

Fonte: Base de dados do IBGE, Organizado por: SILVA, D.V.F.

O município de Ubiratã foi criado por meio da Lei 4.425 de 25 de julho de 1960, mas apenas no dia 04 de novembro de 1961 conquistou sua emancipação política, com instalação definitiva em 15 de dezembro de 1963 (PREFEITURA MUNICIPAL DE UBIRATÃ, 2018). A figura 2 apresenta uma visão geral de alguns pontos do município.

A partir da década de 1960, depois do cultivo de hortelã, o algodão tornou-se a principal atividade econômica. De acordo com Hespanhol (1993) predominou em Ubiratã a agricultura tradicional, voltada para a subsistência, mas em alguns casos voltadas para o mercado externo, como o próprio plantio de algodão. 
FIGURA 2 - IMAGENS DO MUNICÍPIO DE UBIRATÃ

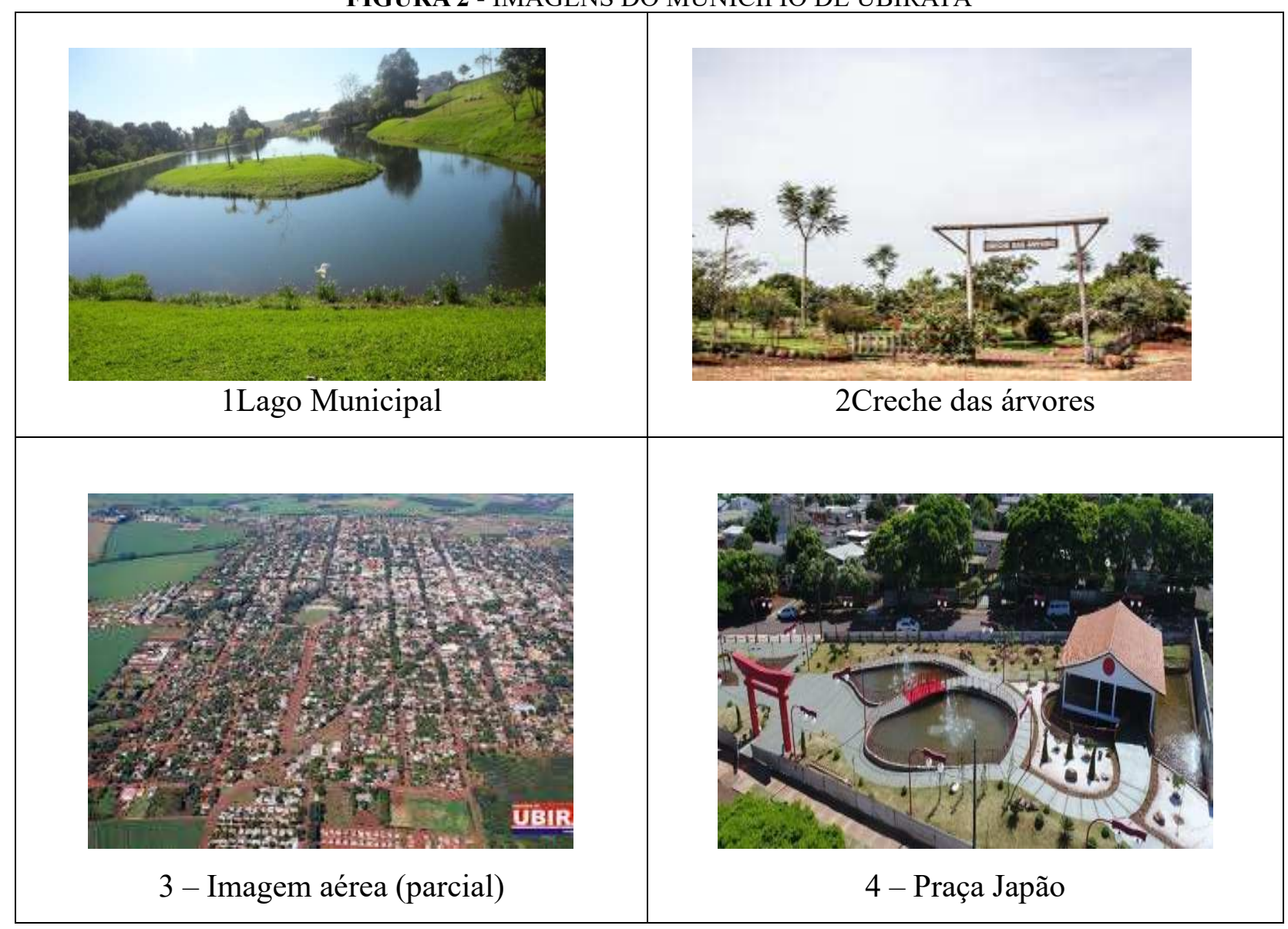

Fonte: Prefeitura Municipal de Ubiratã (2019).

Até a década de 1960 o município foi considerado uma área de atração populacional em virtude do processo de ocupação das terras para a prática da agricultura. A partir da década de 1970, num contexto geral verificado em inúmeros municípios situados no interior do Paraná, Ubiratã passou a vivenciar uma perda significativa de população que continuou nas décadas seguintes. Em valores absolutos a população passou de 40.253 habitantes em 1970, para 21.558 em 2010 (tabela 1).

A redução de população é mais evidente quando comparamos a população urbana e a rural. O campo perdeu muitos habitantes por conta do processo de êxodo rural, ocasionado pela modernização da agricultura, que substituiu a força de trabalho braçal por máquinas e insumos químicos. Já a população urbana cresceu entre os censos demográficos de 1970, 1980 e 1991, tendo uma pequena queda nos anos 2000. No censo de 2010 foi observado crescimento da população urbana (Tabela 1).

No entanto, depois de 2010, o que se presume é que a população total tenha aumentado em razão, como já mencionado, da criação de novos postos de trabalho a partir da implantação da Cooperativa Unitá em 2013, bem como das demais atividades que são impulsionadas por ela. 
TABELA 1 - POPULAÇÃO DE UBIRATÃ DE 1970 A 2010

População

Décadas

$\begin{array}{lccccc} & 1970 & 1980 & 1991 & 2000 & 2010 \\ \text { Total } & 40.253 & 27.726 & 26.828 & 22.593 & 21.558 \\ \text { Urbana } & 6.719 & 13.966 & 18.311 & 17.633 & 18.397 \\ \text { Rural } & 33.534 & 13.760 & 8.517 & 4.960 & 3.161\end{array}$

Fonte: Censos Demográficos (IBGE).

$\mathrm{Na}$ Tabela 2 podemos destacar a projeção populacional estimada pelo IBGE para o município de Ubiratã em 2020. De acordo com as análises do referido instituto, Ubiratã perderia população em relação ao censo de 2010, mais precisamente 649 habitantes. No entanto, as projeções são baseadas, principalmente, no comportamento pretérito dos dados de população. De acordo com o contexto municipal atual e ao fato da criação de empregos a partir da implantação de uma grande empresa no município (a cooperativa Unitá), a hipótese é de que a estimativa de 2020 não condiz com a dinâmica populacional atual (trataremos especificamente esse tema nos próximos item do artigo).

De acordo com a Tabela 2, o Índice de Desenvolvimento Humano (IDH) do município de Ubiratã é de 0.739 , levemente abaixo da média do Paraná. O PIB per capita atingiu em 2018 o valor de $\mathrm{R} \$ 44.835$, acima da média paranaense que foi de R 38.773 (IBGE/IPARDES, 2021).

TABELA 2 - DADOS POPULACIONAIS E ECONÔMICOS DO MUNICÍPIO DE UBIRATÃ

\begin{tabular}{ccccccc}
\hline $\begin{array}{c}\text { População do } \\
\text { município em } \\
\mathbf{2 0 1 0}\end{array}$ & $\begin{array}{c}\text { População } \\
\text { Estimada em } \\
\mathbf{2 0 2 0}\end{array}$ & $\begin{array}{c}\text { População } \\
\text { ocupada em } \\
\mathbf{2 0 1 8}\end{array}$ & $\begin{array}{c}\text { PIB per } \\
\text { capita em R\$ } \\
\mathbf{2 0 1 8}\end{array}$ & $\begin{array}{c}\text { Salário médio } \\
\text { mensal em 2018 }\end{array}$ & $\begin{array}{c}\text { IDH } \\
\text { Ubiratã } \\
\mathbf{2 0 1 0}\end{array}$ & $\begin{array}{c}\text { IDH } \\
\text { Paraná } \\
\mathbf{2 0 1 0}\end{array}$ \\
\hline 21.558 & 20.909 & $36,2 \%$ & 44.835 & 1,9 & 0.739 & 0.749 \\
& & & Salário Mínimo & \\
\hline
\end{tabular}

Fonte: IBGE/IPARDES, 2021.

Conforme os dados disponíveis na Tabela 3, o município vem apresentando ao longo dos anos uma redução significativa no percentual de pessoas na extrema pobreza e na pobreza, assim como redução da desigualdade, registrada pelo índice de Gini (valores próximos de zero indicam pequena desigualdade e valores próximos de uma maior desigualdade na distribuição da renda). A geração de 
empregos e as políticas públicas sociais são fatores determinantes para diminuição dos indicadores de pobreza.

Tabela 3 - Índices de Renda, Pobreza e Desigualdade no município de Ubiratã

TABELA 3 - ÍNDICES DE RENDA, POBREZA E DESIGUALDADE NO MUNICÍPIO DE UBIRATÃ

\begin{tabular}{cccc}
\hline Indicadores & $\mathbf{1 9 9 1}$ & $\mathbf{2 0 0 0}$ & $\mathbf{2 0 1 0}$ \\
\hline \% de extremamente pobres & 14,36 & 11,10 & 1,81 \\
\% de pobres & 41,96 & 28,78 & 7,95 \\
Índice de Gini & 0,63 & 0,54 & 0,46 \\
\hline
\end{tabular}

Fonte: PNUD, 2010.

Em relação à economia do município, sua base é sustentada pela agropecuária, predominando as seguintes atividades: produção de soja; milho; trigo; arroz e feijão. Já a agroindústria avícola vem se destacando desde 2013, época de instalação da Cooperativa Unitá. Em 2018 a produção de aves (galináceos) em Ubiratã foi de 2.640 .000 cabeças, o que equivale a $0,69 \%$ da produção do Paraná.

\section{MODERNIZAÇÃo DA AGRICULTURA E A REDUÇÃO DE POPULAÇÃo}

A modernização da agricultura foi um evento que rompeu paradigmas e modificou a organização social no campo em escala mundial. Esse processo ocorreu de forma diferenciada no tempo e no espaço. No Brasil, de acordo com Moro (2001), a modernização começou a ser viabilizada na década de 1960, como uma política de Estado e com forte influência do comércio exterior.

No Paraná a questão climática teve influência na modernização da agricultura, apesar de não ser o principal agente desse processo que foi predominantemente político e econômico. As intensas geadas ocorridas nos meses de inverno fragilizaram as plantações de café, cultura agrícola dominante no estado, sobretudo na região Norte.

[...] foi a geada de 17 de julho de 1975, de grande intensidade, que praticamente dizimou os cafezais do Norte do Paraná, acelerando o processo de sua erradicação e a consequente substituição por outras atividades produtivas. Assim, em curto espaço de tempo, a cafeicultura paranaense sofreu uma redução em torno de 1,3 milhão de hectares, contribuindo, sobremaneira, para acelerar a mobilidade espacial da população, em especial, nas tradicionais áreas cafeeiras do estado (MORO, 2001, p.110-111). 
A cafeicultura foi representativa na agricultura paranaense até meados da década de 1970 . Nesse período as lavouras de café demandavam expressiva mão de obra, o que garantia um elevado índice de população vivendo no meio rural. Porém, a conjuntura foi alterada com o processo de modernização da agricultura.

A década de 70 assinala sensíveis transformações no perfil geoeconômico do Estado: a modernização da agricultura, com a substituição, em larga escala, da cafeicultura por pastagens e pelo sistema agrícola de rotação de culturas soja-trigo; o desenvolvimento e consolidação do setor agroindustrial; a implantação do distrito industrial de Curitiba contribuíram para isso (MORO, 1998, p. 1).

Nesta conjuntura começou a ganhar força o cultivo do binômio soja-trigo em substituição ao café e a introdução de maquinário na agricultura na Mesorregião Centro Ocidental Paranaense. Yokoo (2013) verificou que a produção de soja contribuiu para a modernização no campo, o que refletiu na mudança nas condições de trabalho. O trabalho dos colonos nos cafezais foi substituído pelo trabalho das máquinas. Restaram poucos trabalhadores nas fazendas que se modernizaram.

$\mathrm{O}$ advento dos equipamentos mecanizados para o trabalho no campo (tratores, colheitadeiras e caminhões) e produtos químicos (agrotóxicos) reduziu significativamente a necessidade de trabalhadores braçais, tornando uma imensa população rural desempregada. Assim, começa uma acelerada migração do campo para cidade, chamado de êxodo rural.

$\mathrm{Na}$ avaliação crítica elaborada por Graziano da Silva (1982), a modernização da agricultura foi conservadora e dolorosa, visto que beneficiou apenas algumas regiões e culturas em detrimento de outras, ou seja: “[...] uma modernização induzida através de pesados custos sociais e que só vinga pelo amparo do Estado" (GRAZIANO DA SILVA, 1982, p. 40).

A mecanização agrícola gerou um elevado índice de desemprego no campo em inúmeros municípios do interior do Paraná, fato que intensificou os fluxos migratórios para a cidade, em especial para as cidades mais dinâmicas como, por exemplo, São Paulo e Curitiba. A população migrou para os centros urbanos maiores em busca de melhores oportunidades, uma vez que as cidades de origem não ofereciam políticas públicas visando à manutenção e fixação dessa população. Na Mesorregião Centro Ocidental Paranaense:

Os impactos desse processo sobre a dinâmica demográfica foram intensos e imprimiram na mesorregião características que a situam como área de esvaziamento populacional - em 21 municípios houve, nos anos 90, redução da população total. Mesmo Campo Mourão, o principal centro da mesorregião, apresentou taxa de crescimento inferior a $0,5 \%$ ao ano, indicando dificuldades de reter o aumento populacional que decorreria do crescimento vegetativo de sua população. Esse 
comportamento se estendeu inclusive às áreas urbanas da região, notando-se forte desaceleração das taxas de crescimento, bem como perdas populacionais absolutas (IPARDES, 2004, p. 14).

As mudanças ocorridas nas décadas de 1970, 1980 e 1990 contribuíram para a atual situação em que se encontram grande parte dos municípios de pequeno porte demográfico no interior do Paraná. Um estado que poderíamos classificar como sendo um "mosaico", visto que, de acordo com estudos de Fresca (2013), dos 399 municípios, 80\% possuem pouca expressividade. No Paraná poucos municípios se destacam nacionalmente, como são os casos de Curitiba, Londrina, Maringá, Ponta Grossa, Paranaguá e Cascavel.

O resultado da ausência ou da ineficiência das políticas públicas foi o desenvolvimento geográfico desigual que se constituiu em um problema para a gestão territorial. O governo do Paraná vem, ano após ano, potencializando os seus investimentos em poucos municípios que se tornaram os mais desenvolvidos. Por sua vez, a maioria dos municípios recebeu poucos investimentos e enfrenta, há algumas décadas, sérios problemas sociais, entre eles a evasão populacional.

\section{FORMAÇÃO DOS COMPLEXOS AGROINDUSTRIAIS}

A avicultura é um ramo em crescimento tanto no mercado interno como também no externo. Um dos principais motivos é que a carne de frango é uma das mais consumidas no mundo. O seu baixo custo, comparado a outras carnes, contribui para elevar ainda mais o consumo.

A origem da avicultura como atividade econômica no país está vinculada a fundação em 1913, na cidade de São Paulo, da sociedade brasileira de avicultura. A sociedade tinha como um dos seus objetivos desenvolver a avicultura no Brasil. A associação, ainda que de forma incipiente, conseguiu trazer novos rumos para o setor (MALAVAZZI, 1977). A partir da criação da associação a avicultura foi se intensificando e se espalhando pelo país.

No ano de 1965 foi criado o Fundo Geral para Agricultura e Indústria (FUNAGRI), através do Decreto 56.835, resultado da política agroindustrial brasileira que ajudou a fomentar o setor, além das articulações com empresas internacionais (MALAVAZZI, 1977).

Atualmente, a avicultura é uma das principais atividades agropecuárias da economia brasileira. Segundo dados de 2014 apresentados pelo Ministério da Agricultura, Pecuária e Abastecimento (MAPA), o Brasil exportou carne de frango para 142 países. De acordo com dados da 
Associação Brasileira de Proteína Animal (ABPA, 2015), o Brasil foi o terceiro maior produtor da carne de frango no ano de 2014, ficando atrás apenas dos Estados Unidos e da China.

Aproveitando-se da expansão da atividade pelo país e no estado do Paraná, foram instalados aviários em Ubiratã e região para atender a demanda industrial. Os produtores se associam à cooperativa e fazem investimentos financeiros para construção dos galpões. As cooperativas, segundo Fresca (2013, p. 22), presentes na maior parte da região Sul brasileira, "[...] colocam-se como mecanismos que conseguem até certo ponto, competir com aquelas internacionais, já que tem estratégias bastante expressivas e complexas de atrair seus cooperados".

\section{A INFLUÊNCIA DA COOPERATIVA UNITÁ NA MOBILIDADE DA POPULAÇÃO PARA UBIRAT $\tilde{A}$}

No ano de 2011 a Copacol, Coagru e Cooperflora criaram a Cooperativa Central Unitá, no município de Ubiratã. Em 2013 foi inaugurada a Unidade Industrial de Aves (figura 3), para o abate e processamento de carne de frango. A Unitá está localizada na BR 369, no Km 439. Os associados das cooperativas Copacol e Coagru criam o frango nos aviários localizados na área rural, para posteriormente serem encaminhados para o abate na Unitá.

\section{FIGURA 3 - IMAGEM AÉREA DA COOPERATIVA UNITÁ}

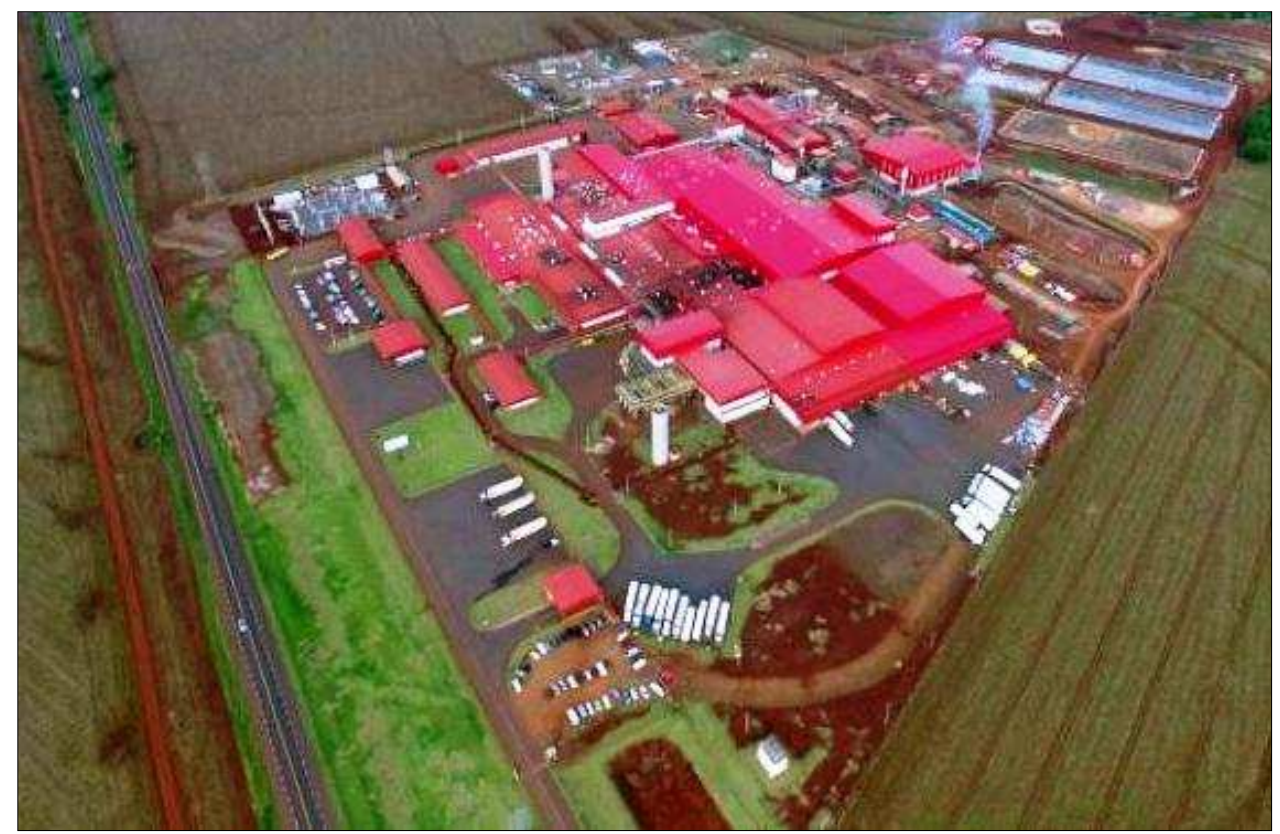

Fonte: Unitá Cooperativa Central, 2018. 
$\mathrm{Na}$ Unitá as atividades estão organizadas em dois turnos, com produção de 10 mil toneladas de carne de frango por mês. São abatidas 230 mil aves por dia. De acordo com o gráfico 1, em 2018 foram abatidas 52,5 milhões de aves. Nota-se um grande salto no abate entre 2013 e 2017. Porém, no ano de 2018 houve queda, uma diferença negativa de 1,6 milhões de aves. A cooperativa atribui o fato a greve dos transportes que acarretou na suspensão das atividades da cooperativa por uma semana (UNITÁ COOPERATIVA CENTRAL, 2018).

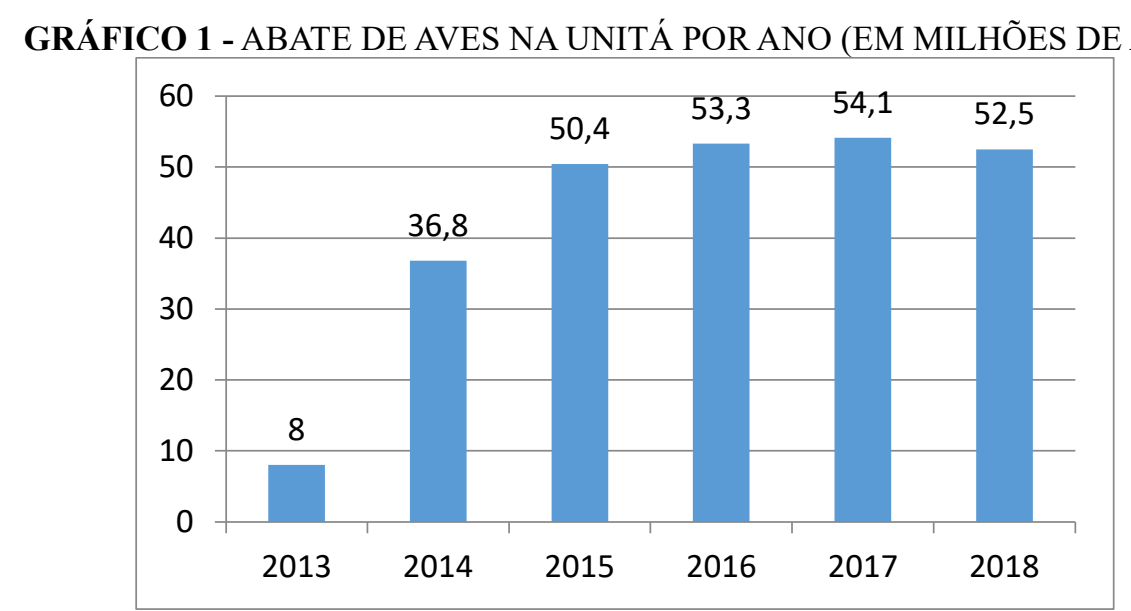

Fonte: Unitá Cooperativa Central, 2018., Organizado por: SILVA, D.V.F

De acordo com os números expostos nos gráficos 2 e 3, a Unitá gera mais de 2,6 mil empregos diretos. O número total de trabalhadores cresceu entre 2013 e 2018. A Unitá processa e embala seus produtos com a marca Copacol. Os produtos são comercializados no Brasil e em mais de 40 países, sendo que $70 \%$ da produção tem como destino o mercado externo. Em 2018 foram exportadas 82,6 mil toneladas de carne de frango.

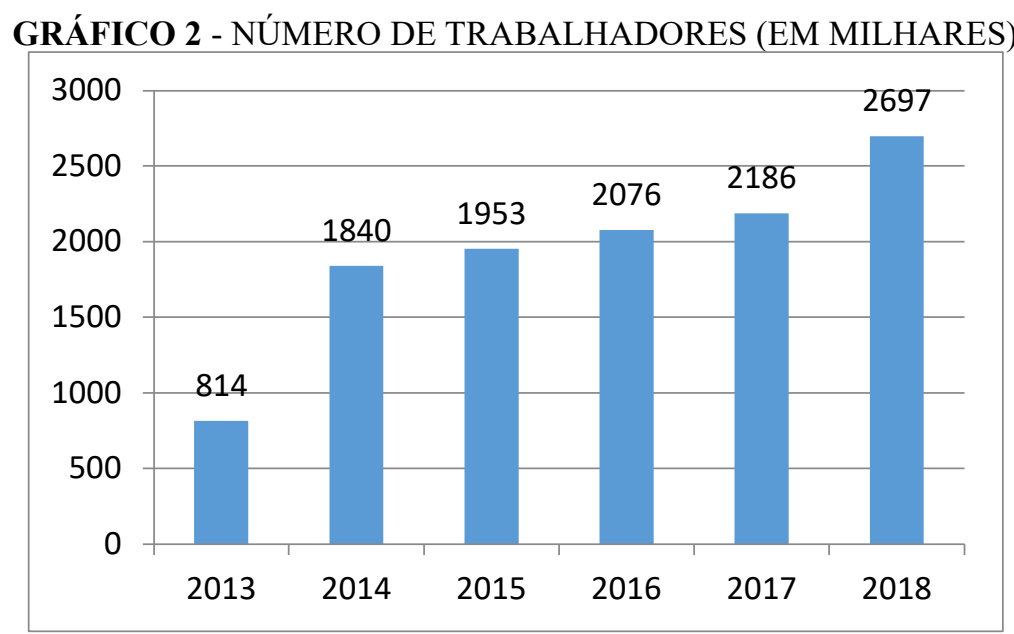

Fonte: Unitá Cooperativa Central, 2018, Organizado por: SILVA, D.V.F 


\section{GRÁFICO 3 - EVOLUÇÃO DAS EXPORTAÇÕES DE CARNE DE FRANGO (MIL/T)}

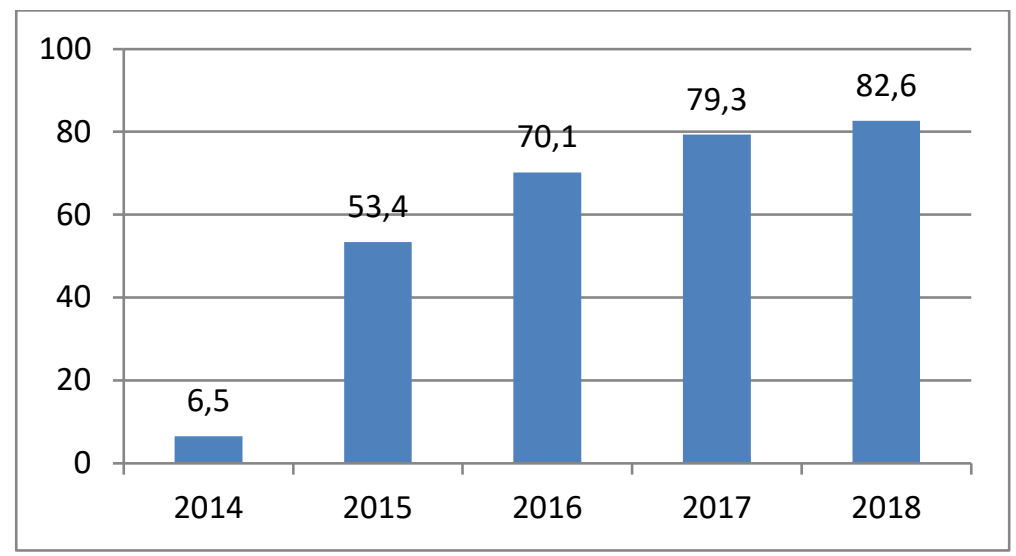

Fonte: Unitá Cooperativa Central, 2018, Organizado por: SILVA, D.V.F

O continente africano é o principal destino no ranking de exportação da Unitá, em especial para os seguintes países: Angola; África do Sul e Namíbia. Na sequência aparecem os países do Oriente Médio, com destaque para toda a região do Golfo Pérsico: Iraque; Emirados Árabes e Jordânia. Na Ásia a Unitá exporta seus produtos para países como o Japão e Hong Kong. No continente americano para as ilhas do Caribe e para Chile e México (UNITÁ COOPERATIVA CENTRAL, 2018).

É notório que o município de Ubiratã em tempos de globalização está cada vez mais inserido em uma rede internacional de produção e exportação de carne de frango. Com o aprofundamento do processo de globalização não é mais possível analisar as transformações vivenciadas em um lugar sem avaliar a influência de fatores externos. A produção de carne de frango e a geração dos empregos em Ubiratã, bem como a sua expansão está fortemente atrelada ao mercado internacional.

Diante dos números obtidos é possível verificar o crescimento da avicultura no município de Ubiratã nos últimos seis anos. Esse crescimento tem gerado empregos para a população local, atraído trabalhadores dos municípios próximos que realizam a migração pendular, assim como trabalhadores oriundos de diferentes localidades distantes de Ubiratã.

No quadro 1 , bem como na figura 4 , estão organizados o número de trabalhadores que mudaram para Ubiratã para trabalhar na Unitá. Evidencia-se que há pessoas vindas de todas as regiões do Brasil, com maior concentração das regiões Sul e Sudeste.

Os dados obtidos indicam que existem migrantes oriundos de todas as regiões do Brasil. Na região Sul podemos identificar, além do Paraná, migrantes provenientes de Santa Catarina e Rio Grande do Sul. Seguindo para o Sudeste identificamos três Estados: São Paulo; Rio de Janeiro e Minas Gerais. O destaque foi para o estado de São Paulo, totalizando 22 migrantes de 10 municípios 
diferentes. No Centro-Oeste temos os estados de Mato Grosso e Goiás, com destaque para Mato Grosso, totalizando nove migrantes de seis municípios diferentes. A região Nordeste apresenta índice migratório menor, com origem nos estados da Bahia, Alagoas, Pernambuco e Piauí. Na região Norte apenas Rondônia. Também foi identificado um imigrante proveniente da República do Paraguai, país que faz fronteira com o Brasil.

QUADRO 1 - MOBILIDADE DA POPULAÇÃO PARA UBIRATÃ ENTRE 2013 E 2018

\begin{tabular}{|c|c|c|c|}
\hline $\mathbf{B R}$ & REGIÃO / ESTADO & $\mathrm{N}^{\circ}$ DE MUNICÍPIOS & $\mathrm{N}^{\circ}$ DE MIGRANTES \\
\hline \multicolumn{4}{|l|}{ SUL } \\
\hline 01 & Paraná & 46 & 114 \\
\hline 02 & Santa Catarina & 03 & 03 \\
\hline 03 & Rio Grande do Sul & 01 & 01 \\
\hline \multicolumn{4}{|c|}{ SUDESTE } \\
\hline 01 & São Paulo & 10 & 22 \\
\hline 02 & Rio de Janeiro & 01 & 01 \\
\hline 03 & Minas Gerais & 03 & 03 \\
\hline \multicolumn{4}{|c|}{ CENTRO-OESTE } \\
\hline 01 & Goiás & 01 & 01 \\
\hline 02 & Mato Grosso & 06 & 09 \\
\hline \multicolumn{4}{|c|}{ NORDESTE } \\
\hline 01 & Bahia & 01 & 01 \\
\hline 02 & Alagoas & 01 & 01 \\
\hline 03 & Pernambuco & 02 & 02 \\
\hline 04 & Piauí & 01 & 01 \\
\hline \multicolumn{4}{|l|}{ NORTE } \\
\hline 01 & Rondônia & 03 & 05 \\
\hline \multicolumn{4}{|c|}{ OUTROS PAÍSES } \\
\hline PAÍS & Paraguai & 01 & 01 \\
\hline \multicolumn{4}{|c|}{ TOTAL } \\
\hline 02 Países & 13 Estados brasileiros & 80 municípios & 165 migrantes \\
\hline
\end{tabular}

Fonte: Unitá Cooperativa Central, 2018, Organizado por: SILVA, D.V.F 
FIGURA 4 - FLUXOS DE MOBILIDADE PARA TRABALHAR NA UNITÁ - UBIRATÃ
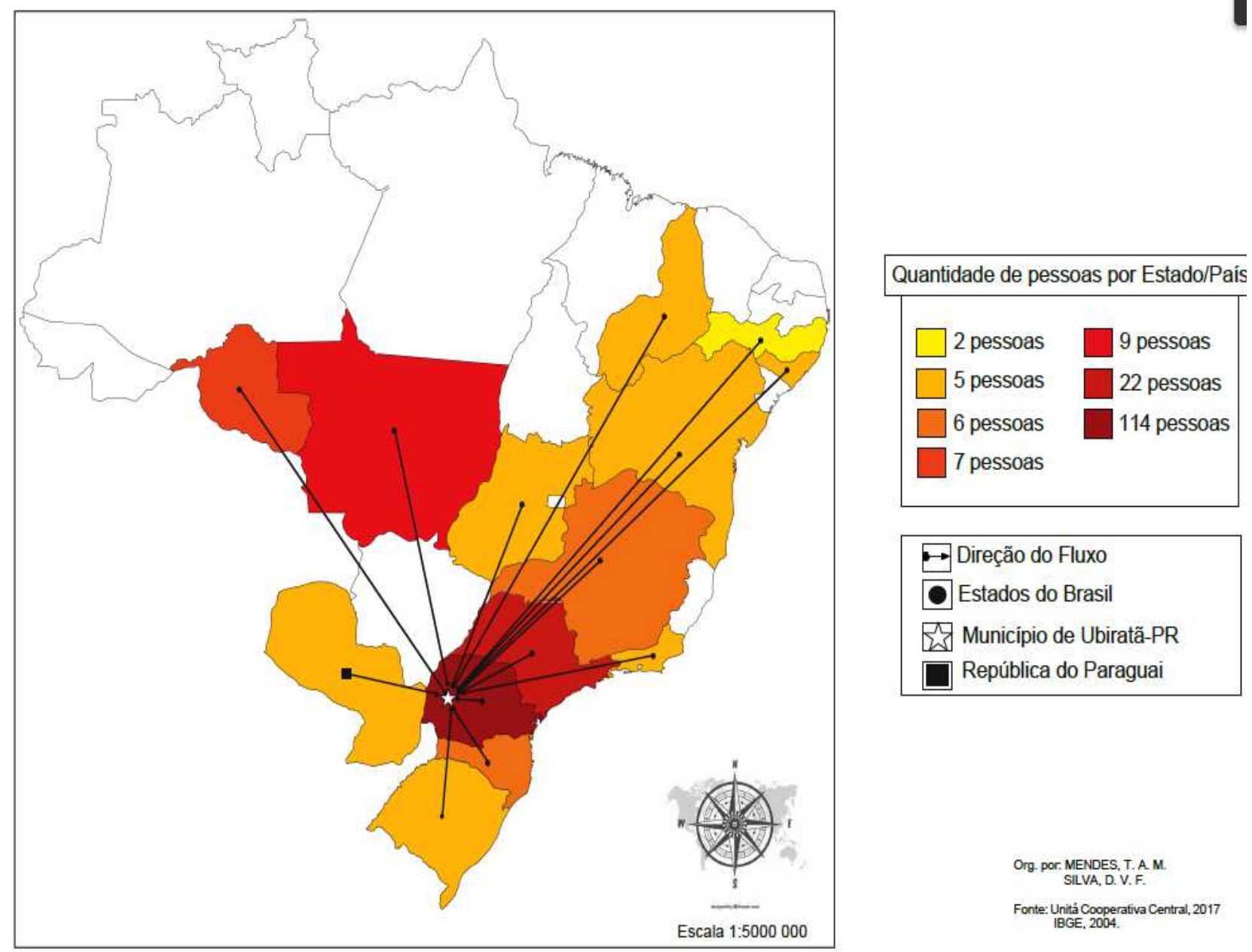

$\rightarrow$ Direção do Fluxo

Estados do Brasil

Município de Ubiratã-PR

República do Paraguai

Fonte: Unitá Cooperativa Central, 2018, Organizado por: SILVA, D.V. F

Com relação ao estado do Paraná os migrantes vieram de 46 municípios diferentes, totalizando 114 pessoas. Na Mesorregião Centro Ocidental Paranaense que é composta por vinte e cinco municípios foram identificados trabalhadores vindos de: Altamira do Paraná, Araruna, Boa Esperança, Campina da Lagoa, Campo Mourão, Engenheiro Beltrão, Goioerê, Iretama, Janiópolis, Juranda, Mamborê, Nova Cantu e Roncador.

Com base nas datas de admissão do trabalhador na empresa e das datas em que os migrantes fixaram residência no município de Ubiratã foi possível observar que muitas dessas pessoas originárias da Mesorregião Centro Ocidental Paranaense começaram a trabalhar praticando a chamada migração pendular, também conhecida como migração diária, ou seja, o trabalhador se deslocava para Ubiratã e voltava todos os dias para o seu município de origem. Posteriormente fixou residência em Ubiratã. Outro caso é do migrante que primeiro fixou residência no município e logo 
em seguida, num período não inferior a seis meses, já estava trabalhando na cooperativa. Os fatos relatados demonstram que a cooperativa é uma importante criadora de postos de trabalho em âmbito regional.

Analisando o caso do estado do Paraná, nota-se que a maioria da população migrante veio dos chamados municípios periféricos. De acordo com Costa e Rocha (2013, p. 50) os municípios periféricos apresentam como características: “[...] esvaziamento populacional, subordinação territorial, dependência econômica e indicadores sociais críticos". Os fatores elencados estimulam a mobilidade da população.

Apesar de sua classificação como município periférico, Ubiratã, diante do atual contexto, começa a traçar, gradualmente, a transição de município periférico para intermediário. Nesse contexto, acredita-se que a presença da Cooperativa Unitá e a expansão da avicultura tem contribuído para dinamizar a economia, gerando novos postos de trabalho, elevando a arrecadação de impostos e estimulando o comércio local.

Porém, é preciso reforçar que trata-se de um processo marcado pela mobilidade forçada, cujos trabalhadores ficam a mercê do planejamento e dos interesses dos empregadores. Não vemos uma mobilidade pautada na vontade pessoal e sim um fenômeno caracterizado pela necessidade de sobrevivência, forçada por um modelo de desenvolvimento desigual e contraditório, pautado nos interesses capitalistas.

\section{CONSIDERAÇÕES FINAIS}

A partir da pesquisa realizada foi possível observar que a instalação da cooperativa Unitá no município de Ubiratã tem gerado empregos para a população local e atraído população de diferentes regiões do país. Isso vem contribuindo possivelmente para reverter o quadro de redução de população total do município verificado desde 1970. Contudo, é necessário insistir que predomina uma mobilidade forçada do trabalho, visto que depende mais das necessidades do empregador e pouco da vontade do trabalhador. Tal assunto foi amplamente discutido por Gaudemar (1977).

As mudanças observadas podem gerar pontos positivos e negativos para o município. Entre as principais alterações positivas estão: geração de empregos; estancamento da evasão populacional; maior arrecadação de impostos; expansão urbana; crescimento do comércio e do setor de serviços. Porém, como pontos negativos destacam-se: baixos salários; mobilidade forçada de trabalhadores; formação de bairros periféricos sem infraestrutura adequada; aumento na demanda por serviços de

$\begin{array}{lll}\text { Silva, Costa e Chies, } 2021 & \text { ISSN 0104-5490 }\end{array}$


educação e saúde no setor público. Na área da saúde, por exemplo, ocorreu aumento no número de atendimentos e não há médicos nem leitos hospitalares suficientes para atender a todos.

No entanto, se a população de Ubiratã de fato aumentou ainda não podemos afirmar, já que o censo demográfico brasileiro mais recente é de 2010 e o de 2020 não ocorreu. Mas verificamos pelas análises, que nos últimos anos o município vem recebendo novos habitantes em virtude da presença da Cooperativa Unitá. Presume-se que grande parte deles tenham migrado acompanhados de suas famílias, elevando o número de habitantes.

Embora não tenha sido discutido as condições de trabalho ofertadas ao trabalhador na cooperativa, por não ser o objetivo da pesquisa, de modo geral, sabe-se que a maioria dos empregos oferecidos no setor de abatedouros de aves são insalubres, com baixa remuneração e elevada rotatividade de trabalhadores. O emprego por si, se não for acompanhado pelo desenvolvimento de outros setores, garante apenas a sobrevivência e não a melhoria das condições de vida da população.

Sendo assim, cabe também verificar as ações do poder público local para oferecer serviços públicos de qualidade para a população, o que se constitui em um desafio, uma vez que o mais importante é o município crescer com qualidade e não apenas em quantidade populacional.

Os resultados indicam que a tendência para os próximos anos é a intensificação desse processo migratório, pois a Cooperativa Unitá vem crescendo no que diz respeito a sua estrutura, número de trabalhadores empregados, abate e exportação de carne de aves. Nessa perspectiva, o processo de transição do município da condição de periférico para intermediário, conforme mencionado anteriormente, com base nos autores já citados, tem grandes chances de se efetivar.

\section{REFERÊNCIAS}

ASSOCIAÇÃO BRASILEIRA DE PROTEÍNA ANIMAL. Relatório Anual, 2015.

BRITO, F.; RIGOTTI, J. I; CAMPOS, J. A mobilidade interestadual da população no Brasil no início do século XXI: mudança no padrão migratório? Minas Gerais, 2012.

COSTA, F. R. Condições periféricas: desenvolvimento geográfico desigual no Paraná. Campo Mourão: Editora da Fecilcam, 2016.

COSTA, F. R. Desenvolvimento local em municípios periféricos. In: BOVO, M. C.; TOWS, R. L.; COSTA, F. R. (Org.). Estudos Urbanos em Perspectivas: reflexões, escalas e desafios. Campo Mourão: editora da Fecilcam, p.49-68, 2013.

COSTA, S. A saga da avicultura brasileira: como o Brasil se tornou o maior exportador mundial de carne de frango. São Paulo: UBABEF, 2011. 
CUNHA, J. M. P. Mobilidade espacial da população: desafios teóricos e metodológicos para o seu estudo. In: CUNHA, J. M. P. (org.) Mobilidade espacial da população: desafios teóricos e metodológicos para o seu estudo. Campinas: NEPO/UNICAM, 2011.

DAMIANI, A. População e geografia. São Paulo: Contexto, 2004.

FRESCA, T. M. O papel das pequenas cidades na rede urbana paranaense. In: BOVO, M.C.; TOWS, R. L.; COSTA, F.R.(Org.). Estudos Urbanos em Perspectivas: reflexões, escalas e desafios. Campo Mourão: editora da Fecilcam, p.27-35, 2013.

GAUDEMAR. J-P. Mobilidade do trabalho e acumulação do capital. Lisboa: editorial estampa, 1977.

GRAZIANO DA SILVA, J. A modernização dolorosa: estrutura agraria, fronteira agrícola e trabalhadores rurais do Brasil. Rio de Janeiro: Zahar, 1982.

HESPANHOL, A. N. A formação sócio espacial da Região de Campo Mourão e dos Municípios de Ubiratã, Campina da Lagoa e Nova Cantu - PR. Boletim de Geografia, Maringá, v. 1, p. 17-28, 1993.

IBGE. Instituto Brasileiro de Geografia e Estatística. Cidades. Disponível em:

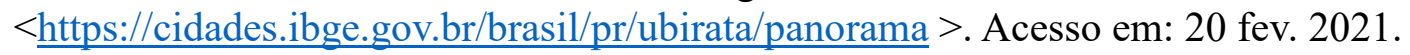

IPARDES. Caderno estatístico no Município de Ubiratã. 2018. Disponível em: $<$ http://www.ipardes.gov.br/cadernos/Montapdf.php?Municipio=80000 >. Acesso em: 10 set. 2018 .

2004.

. Leituras Regionais: mesorregiões geográficas paranaenses: sumário executivo. Curitiba,

MALAVAZZI, G. Avicultura: manual prático. São Paulo: Nobel, 1977.

MINISTÉRIO DA AGRICULTURA, PECUÁRIA E ABASTECIMENTO. Aves. Disponível em: $<$ http://www.agricultura.gov.br/animal/especies/aves $>$. Acesso em: 27 set. 2018.

MORO, D. A. Desenvolvimento econômico e dinâmica da população no Paraná contemporâneo. Boletim de Geografia. v.1, n. 16, 1-55, 1998.

. A Modernização da Agricultura Paranaense. In: Jorge Ulises Guerra Villalobos. (Org.). Geografia Social e Agricultura. Maringá: Universidade Estadual de Maringá, 2001, v. 1, p. 27-60.

PREFEITURA DO MUNICÍPIO DE UBIRATÃ. PARANÁ. Disponível em: $<$ http://ubirata.pr.gov.br/index.php?sessao=b054603368ncb0\&id=1111 > . Acesso em: set. 2018.

ROCHA, M. M. A espacialidade das mobilidades humanas - um olhar para o Norte Central Paranaense. Tese (Doutorado em Geografia) - Universidade Estadual de São Paulo, USP, Brasil, 1998.

SEVERINO, A. J. Metodologia do trabalho científico. São Paulo, Cortez, 2007.

UNITÁ COOPERATIVA CENTRAL. Disponível em: $<$ https://www.unitacentral.com.br/new/downloads/relatoria-anual-2018.pdf $>$. Acesso em: 15 out. 2018.

VILLACA, F. Espaço intra-urbano no Brasil. São Paulo: Studio Nobel: FAPESP: Lincoln Institute, 2001.

YOKOO, E. N. Processo da dinâmica das frentes de ocupação territorial e da paisagem agrária na Mesorregião Centro-ocidental Paranaense. Tese (Doutorado em Geografia) - Universidade Estadual de Maringá, UEM, Brasil, 2013. 